\title{
Crustal S-wave velocity structure of the Yellowstone region using a seismic ambient noise method
}

\author{
Yan Lü $\cdot$ Sidao Ni $\cdot$ Jun Xie $\cdot$ Yingjie Xia $\cdot$ \\ Xiangfang Zeng $\cdot$ Bin Liu
}

Received: 9 July 2013/Accepted: 4 September 2013/Published online: 30 October 2013

(C) The Seismological Society of China, Institute of Geophysics, China Earthquake Administration, and Springer-Verlag Berlin Heidelberg 2013

\begin{abstract}
The Yellowstone volcano is one of the largest active volcanoes in the world, and its potential hazards demand detailed seismological and geodetic studies. Previous studies with travel time tomography and receiver functions have revealed a low-velocity layer in the crust beneath the Yellowstone volcano, suggesting the presence of a magma chamber at depth. We use ambient seismic noise from regional seismic stations to retrieve short-period surface waves and then study the shallow shear velocity structure of the Yellowstone region by surface wave dispersion analysis. We first obtained a crustal model of the area outside of the Yellowstone volcano and then constructed an absolute shear wave velocity structure in combination with receiver function results for the crust beneath the Yellowstone volcano. The velocity model shows a low-velocity layer with shear velocity at around $1.3 \mathrm{~km} / \mathrm{s}$, suggesting that a large-scale magma chamber
\end{abstract}

\section{Y. Lü}

Institute of Geology and Geophysics, Chinese Academy of Sciences, Beijing 100029, China

\section{S. Ni ( $\square)$}

State Key Laboratory of Geodesy and Earth's Dynamics, Institute of Geodesy and Geophysics, Chinese Academy of Sciences, Wuhan 430077, China

e-mail:sdni@whigg.ac.cn

J. Xie $\cdot$ Y. Xia · B. Liu

Mengcheng National Geophysical Observatory, School of Earth and Space Sciences, University of Science and Technology of China, Hefei 230026, China

\section{Zeng}

CAS Key Laboratory of Computational Geodynamics, University of Chinese Academy of Sciences, Beijing 100049, China exists at shallow levels within the crust of the Yellowstone volcanic region.

Keywords Yellowstone $\cdot$ Seismic ambient noise Low-velocity layer

\section{Introduction}

As the world's largest active volcano, the Yellowstone volcano has an eruption cycle of approximately $0.6-0.8$ million years. The caldera was formed by an eruption 0.64 million years ago (Christiansen 2001). Global positioning system (GPS) and interferometric synthetic aperture radar (InSAR) observations of this region show periodic uplift and subsidence of the caldera (Wicks et al. 1998, 2006; Puskas et al. 2007; Chang et al. 2007). Many geophysical studies involving gravity and seismological modeling have been conducted to reveal the crustal structure of this region (Benz and Smith 1984; Miller and Smith 1999; Waite and Smith 2002; Husen et al. 2004; Schutt et al. 2008; Stachnik et al. 2008; Yang et al. 2008; Lin et al. 2012), and these studies suggest that there is a large magma chamber at a depth less than $10 \mathrm{~km}$ beneath the Yellowstone volcanic region. Geochemical studies also support the presence of a magma chamber around $10 \mathrm{~km}$, and rapid ascent of magma is achievable through faulting of the brittle crust without the need of intermediate storage (Girard and Stix 2012). Thus, the potential volcanic hazards create a demand for more detailed study of the volcanic structures beneath the Yellowstone Caldera.

The geographical extent of the magma chamber beneath the Yellowstone region is revealed from both gravity anomalies and geodetic studies (Phillips et al. 1993; Wicks 


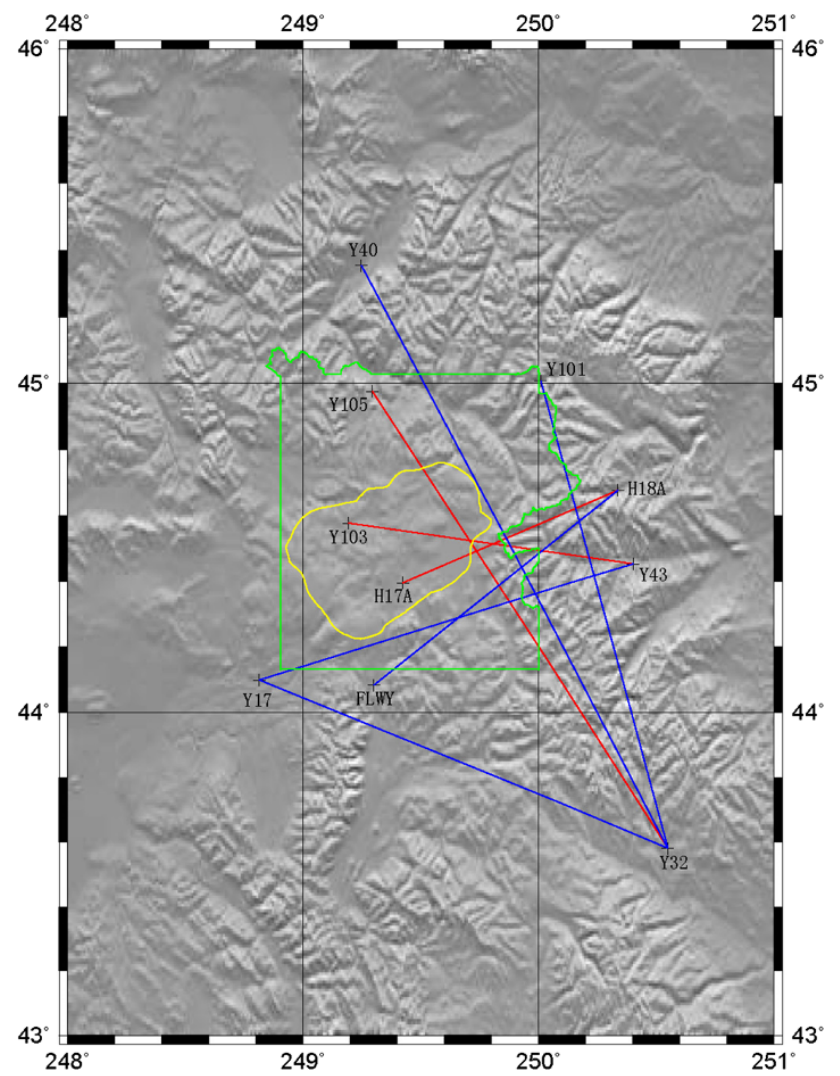

Fig. 1 Stations (crosses) and ray paths of the Yellowstone region. The green line shows the boundary of the Yellowstone National Park; the yellow line represents the Yellowstone Caldera boundary; the red line represents the connecting line between two stations across the Yellowstone volcanic region; and the blue line represents the connecting line that does not cross the Yellowstone volcanic region

et al. 2006), but there are some disagreements among models that delineate the vertical structures. To resolve the detailed vertical velocity structure, Chu et al. (2010) used the receiver function method to demonstrate the existence of a 2-km-thick low-velocity zone (LVZ) at depth around $8 \mathrm{~km}$ beneath the Yellowstone Caldera. Inside the LVZ, the P-wave velocity $(V \mathrm{p})$ is about $2.3 \mathrm{~km} / \mathrm{s}$ and $\mathrm{S}$-wave velocity $(V \mathrm{~s})$ is about $1.1 \mathrm{~km} / \mathrm{s}$, which are very slow as compared to the typical $V \mathrm{p}$ of $6.0 \mathrm{~km} / \mathrm{s}$ and $V \mathrm{~s}$ of $3.5 \mathrm{~km} / \mathrm{s}$ in normal crust (Dziewonski and Anderson 1981). Their model can also explain the anomalous polarization of teleseismic P-waves observed on seismic stations near the edges of the LVZ. However, the receiver function method is only sensitive to the velocity contrast across boundaries, but not to the absolute velocity values (Julia et al. 2000; Xu et al. 2007). The absolute shear velocity is crucial for understanding the physical origin of the LVZ, including the volatile concentration in the magma chamber (Chu et al. 2010). Thus, it is necessary to employ other seismological methods for insight into more accurate shear wave velocities. To resolve the absolute velocity at depths around
$8 \mathrm{~km}$, short-period surface wave dispersion data (period less than $10 \mathrm{~s}$ ) are valuable, but it is difficult to obtain them with earthquake data. Instead, we are able to achieve the absolute velocities at shallow depths of interest using a ambient seismic noise method (Weaver and Lobkis 2001; Campillo and Paul 2003; Shapiro and Campillo 2004; Shapiro et al. 2005; Yao et al. 2006, 2009; Yang et al. 2007, 2010; Moschetti et al. 2007; Bensen et al. 2007, 2008; Lin et al. 2008; Fang and Wu 2009; Zheng et al. 2010, 2011; Gao et al. 2011; Hanson-Hedgecock et al. 2012; Wagner et al. 2012). In contrast to the traditional surface wave method, this seismic ambient noise crosscorrelation method only requires continuous noise recorded by seismic stations and does not only rely on earthquake sources. Therefore, ray coverage can be designed specifically to sample the target study region, and error due to uncertainty in earthquake location and origin time can be avoided, which is not the case when using the classical earthquake surface wave tomography method.

In this paper, we have retrieved surface wave dispersion data from ambient noise recorded on broadband seismic stations in the Yellowstone area, and combined the

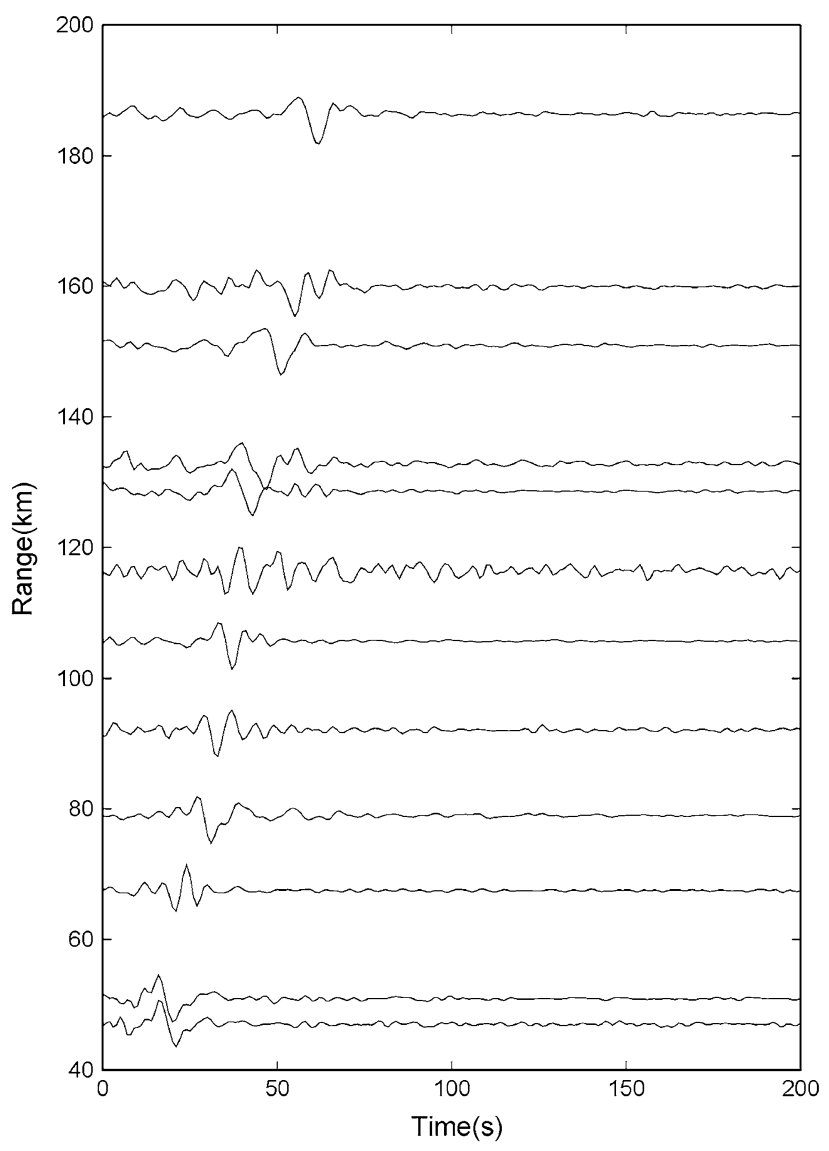

Fig. 2 Surface waveform from seismic ambient noise, from the cross-correlation method 

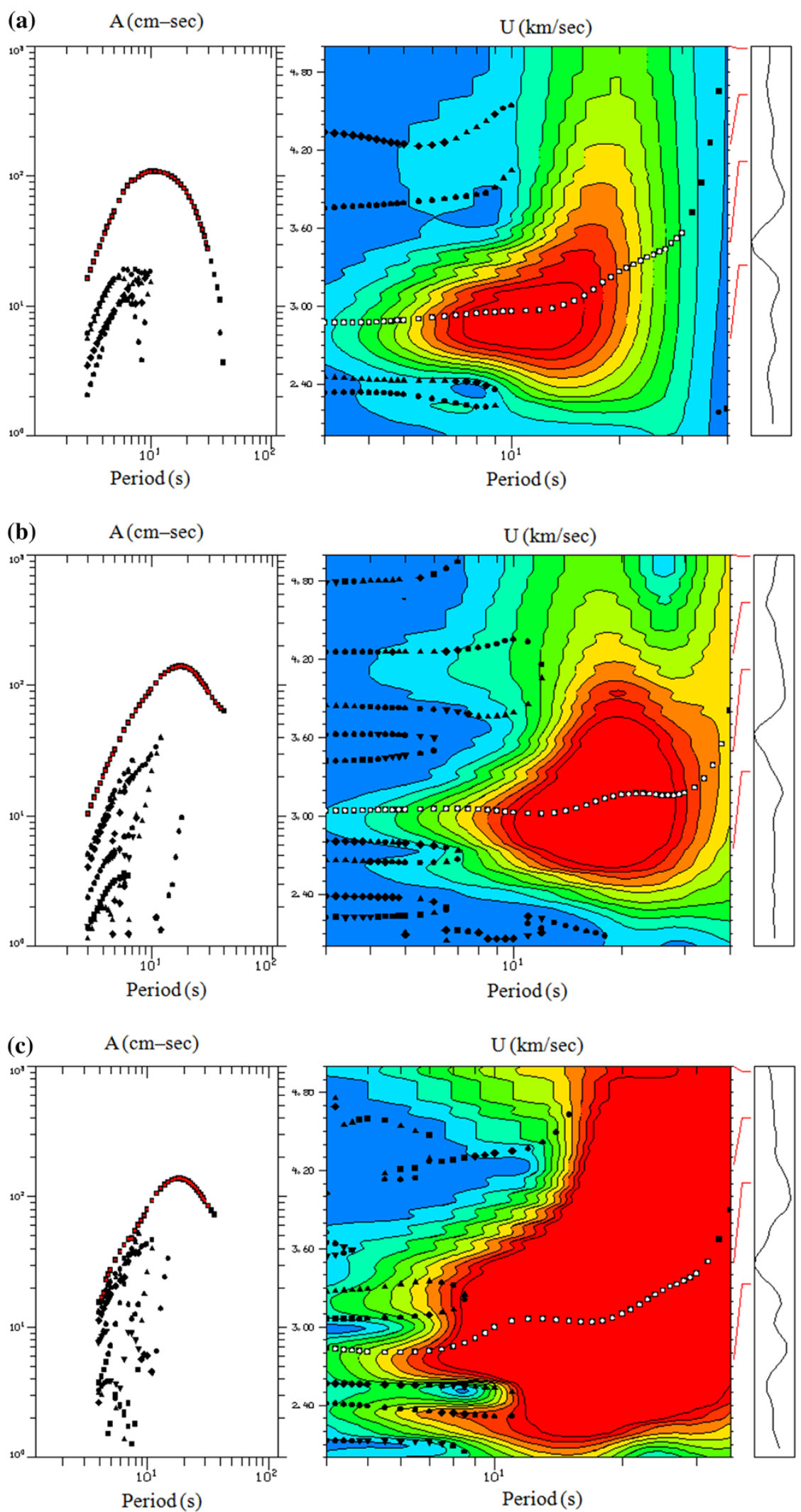

Fig. 3 a-c Surface wave group velocity dispersion curves extracted from FLWY-H18A, Y17-Y32, and Y17-Y43, respectively. (Left) spectral amplitude (right) group dispersion. The black symbols in both panels are local maximum measurements from the multi-taper filtering method. Among the black symbols, the branch corresponding to fundamental model are chosen for the dispersion (white symbols) and spectral amplitude (red symbols) 
information with receiver function analyses of $\mathrm{Chu}$ et al. (2010), to estimate the absolute $S$-wave velocity value of the low-velocity layer. Then, we discuss its implication for a large-scale magma chamber beneath the Yellowstone Caldera.

\section{Data and methods}

Continuous waveform of ambient seismic noise from the XC temporary network was downloaded from IRIS for the entirety of the year 2001. In addition, data recorded by IW and TA networks for the year 2010 were used for dispersion analysis (Fig. 1). We re-sampled the waveform data to $1 \mathrm{sps}$ (sample per second) after removing the instrument response, applied normalization by the one-bit method (Campillo and Paul 2003), and performed cross-correlation to obtain the surface wave between stations following the procedures by Shapiro and Campillo (2004) and Bensen et al. (2007). To guarantee quality of dispersion measurement, we used only noise correlational function (NCFs) with high signal to noise ratio in investigation (Fig. 2). The group velocity dispersion curves were extracted by the software package (CPS) provided by Herrmann and Ammon (2004), which implements the multiple filter method of Dziewonski et al. (1972). The filter function is $\exp \left(-a\left(w-w_{0}\right)^{2} / w_{0}^{2}\right)$, where $w_{0}$ is the center frequency and $a$ is an adjustable parameter used to balance the relationship between the frequency domain and distance. Different $a$ values for different epicentral distances were chosen, as recommended by Herrmann and Ammon (2004).

Surface wave dispersion depends on crustal velocity and density structure; and accordingly, the shear wave velocity can be obtained by inversion from surface wave dispersion curves by adopting an empirical scaling law between $V \mathrm{p}$, density, and shear velocity (Aki and Richards 1980). The surface wave dispersion inversion methods include the least squares method, genetic algorithm (Shi and Jin 1995; Dal Moro et al. 2007), ant colony optimization (Dorigo 1995), and the iterative method. Here, we used the iterative method implemented by the CPS package (Herrmann and Ammon 2004). We denote the velocity structure for the region well outside the volcano area as a normal region model, and the structure inside the volcano area as the LVZ model. First, we used the iterative inversion method to get a crustal model outside the region of the Yellowstone Caldera, assuming a uniform crustal structure in that area. Moreover, we assume that the velocity structure in the caldera region can also be modeled as 1D layered structure. Then, we impose an LVZ on the velocity, assuming that the depth range of the LVZ was well-resolved by Chu et al. (2010). We then change the S-wave velocity of the LVZ to (a)

crustal structure $\mathrm{v}(\mathrm{km} / \mathrm{s})$

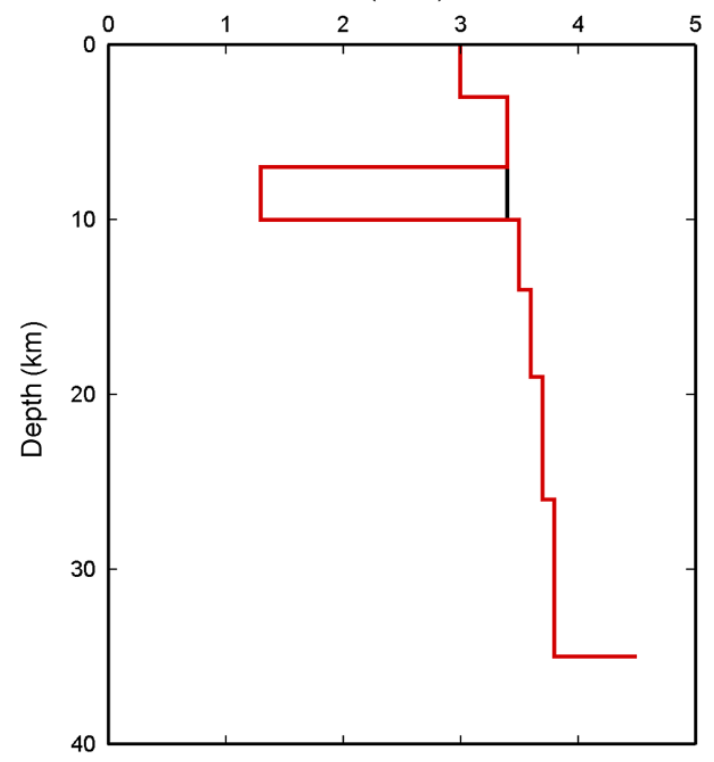

(b) Rayleigh

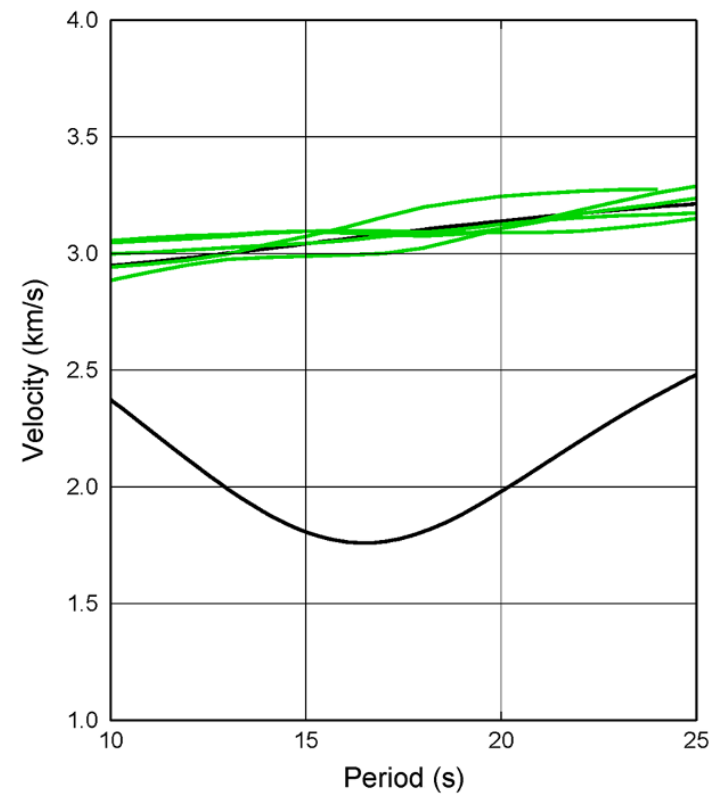

Fig. 4 a Crustal model (normal region model) of the area outside the Yellowstone Caldera region is expressed by the black line; the LVZ model (beneath Yellow stone Caldera) is the red line. b Forward dispersion curves with the model agree well with the observed frequency dispersion curves of Y32-Y17, Y40-Y32, Y17-Y43, Y32Y101, and FLWY-H18A. Forward dispersion curves from the crustal models are represented by the two black lines, and the five green lines represent the observed surface wave dispersion curves of the five rays

fit the observed dispersion. As there are no pairs of seismic stations situated close to the boundary of the LVZ, surface wave paths from ambient seismic noise partially sample the LVZ region and the normal region. We denote ray segment length outside and inside the caldera region as $L 1$ and $L 2$, 


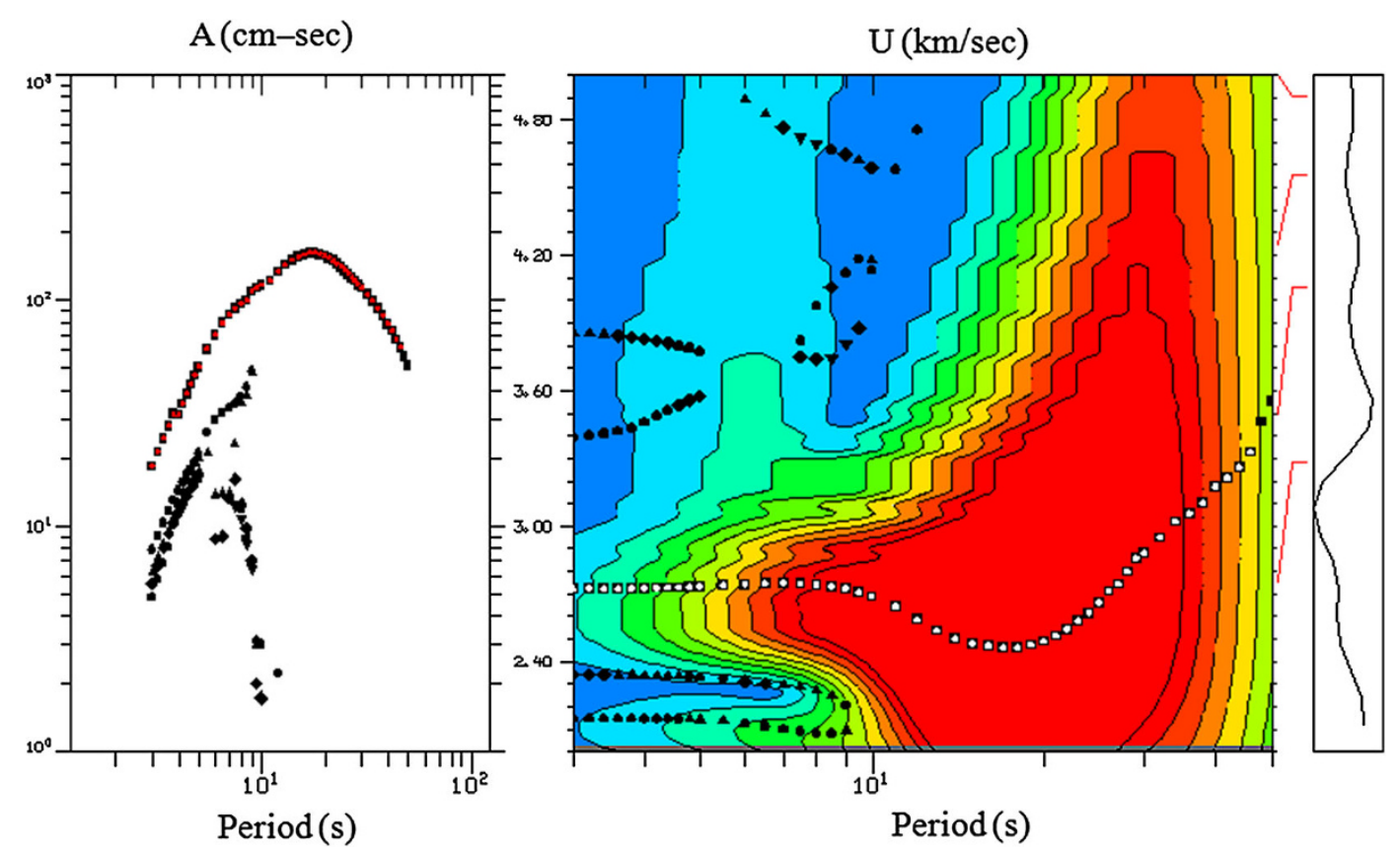

Fig. 5 Surface wave group velocity dispersion curve extracted from the ray path H17A-H18A. The black symbols in both panels are local maximum measurements from the multi-taper filtering method. The white symbols show the branch correspongding to fundamental mode and the red symbols show the spectral amplitude

respectively, and assume that the path-averaged dispersion is given by: $\tilde{v}=(L 1+L 2) /(L 1 / v 1+L 2 / v 2)$. Finally, we compared our results with the observed dispersion curves to test the shear wave velocity of the LVZ.

\section{Results}

To obtain the normal regional model, we used surface wave dispersion of the path between Y17-Y32, Y40-Y32, Y17-Y43, Y32-Y101, and FLWY-H18A, the rays of which do not pass through the magma chamber region (Fig. 3). The normal regional model and the LVZ model are displayed as black and red lines, respectively, in Fig. 4a. The horizontal boundary of the magma chamber is adopted from Chu et al. (2010). The forward dispersion curves from the models are very close to the five observed dispersion curves (Fig. 4b). According to the receiver function study, we set a depth of $8-10 \mathrm{~km}$ as a low-velocity layer. Rays H17A-H18A, Y43-Y103, and Y32-Y105 partially sample the magma chamber area. Figure 5 shows the observed dispersion curves. A comparison of the predicted dispersion curves agree well with the observed dispersion curves of H17A-H18A, Y43-Y103, and Y32Y105 (Fig. 6), which share the following features: when the shear wave velocity in the low-velocity zone is set to be $1.2 \mathrm{~km} / \mathrm{s}$, the forward dispersion curve is lower than that of the observed curve, and is slightly higher than that of the observed curve when the shear wave velocity is set to be $1.4 \mathrm{~km} / \mathrm{s}$. Furthermore, larger changes in the shear velocity in the LVZ result in bigger deviation of the dispersion curves against the observed curve. A low-velocity layer shear velocity of $1.3 \mathrm{~km} / \mathrm{s}$ reproduces the best fit of the forward synthetic dispersion curves with the three observed curves (Figs. 7, 8).

\section{Discussion and conclusions}

Rays H17A-H18A and Y43-Y103 begin at the edge of the magma chamber region and end outside the region. These ray paths are short, and substantial sections are inside the magma chamber region, we assume that the path average approximation is valid. For the case of ray Y32-Y105, the length of the ray segment inside the Yellowstone region is much shorter than the segment outside; the whole ray path may be bent. For this ray, the observed dispersion appeared to be consistent at $1.4 \mathrm{~km} / \mathrm{s}$. At this point, we have not considered the probable effect of surface ray bending effects. In fact, considering the effect of Snell's law, this ray could be consistent when the velocity was $1.3 \mathrm{~km} / \mathrm{s}$ in LVZ. From the results of these rays, we proposed that the shear wave velocity of magma chamber is approximately $1.3 \mathrm{~km} / \mathrm{s}$, within the range of $1.2-1.4 \mathrm{~km} / \mathrm{s}$. This value is consistent with Chu et al. (2010), but a little bit larger. The study by Bensen et al. (2008) also reveals LVZs in the 
(a)

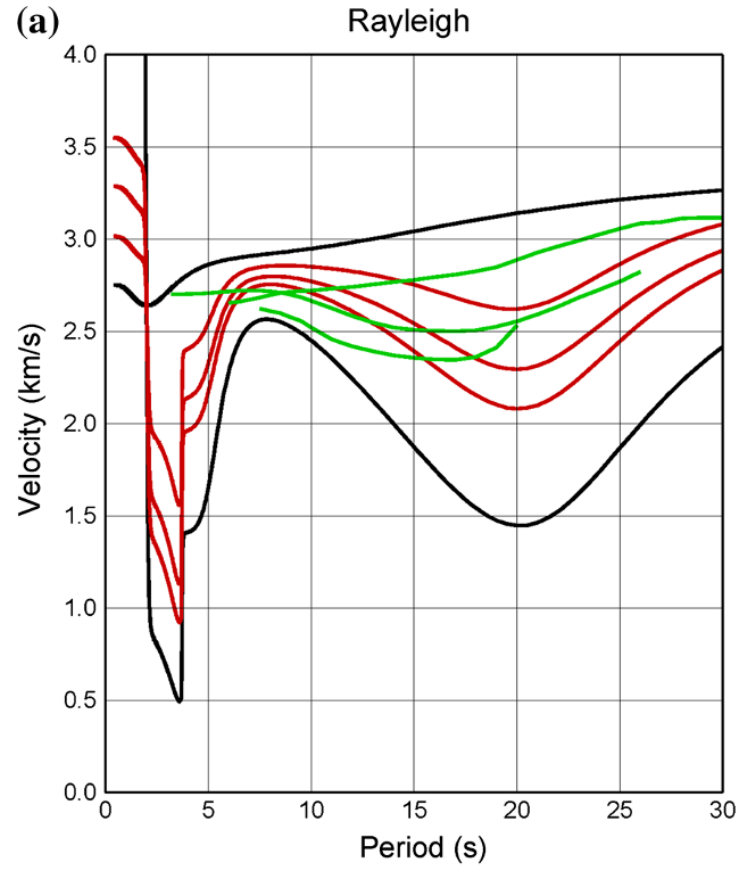

(c)

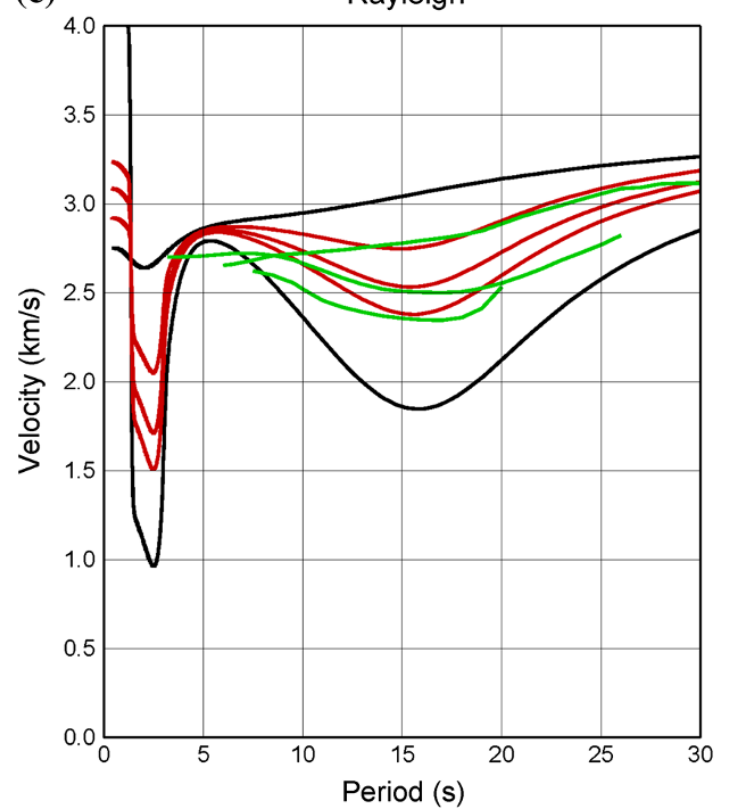

(b)

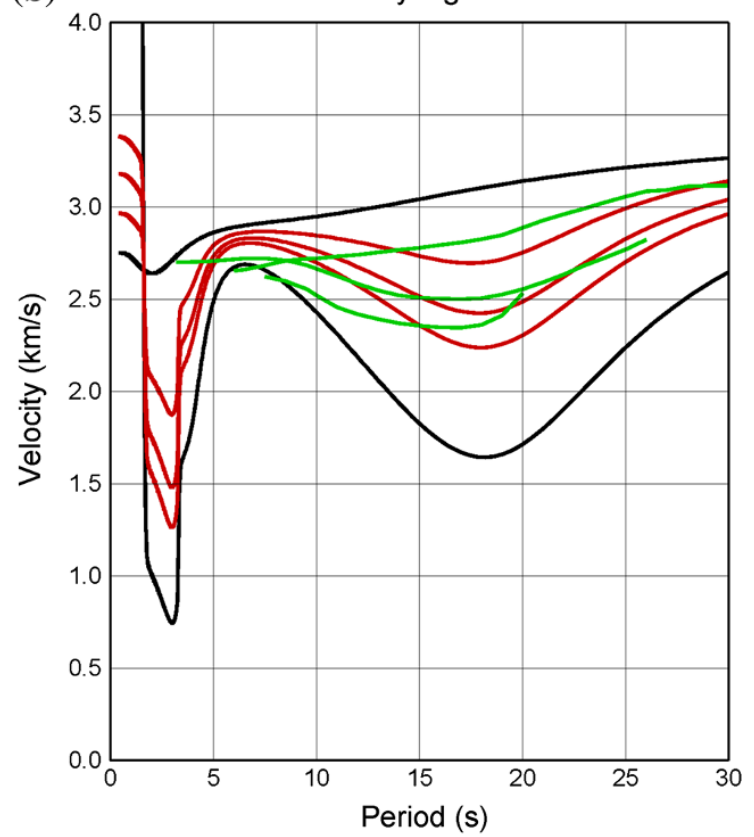

(d)

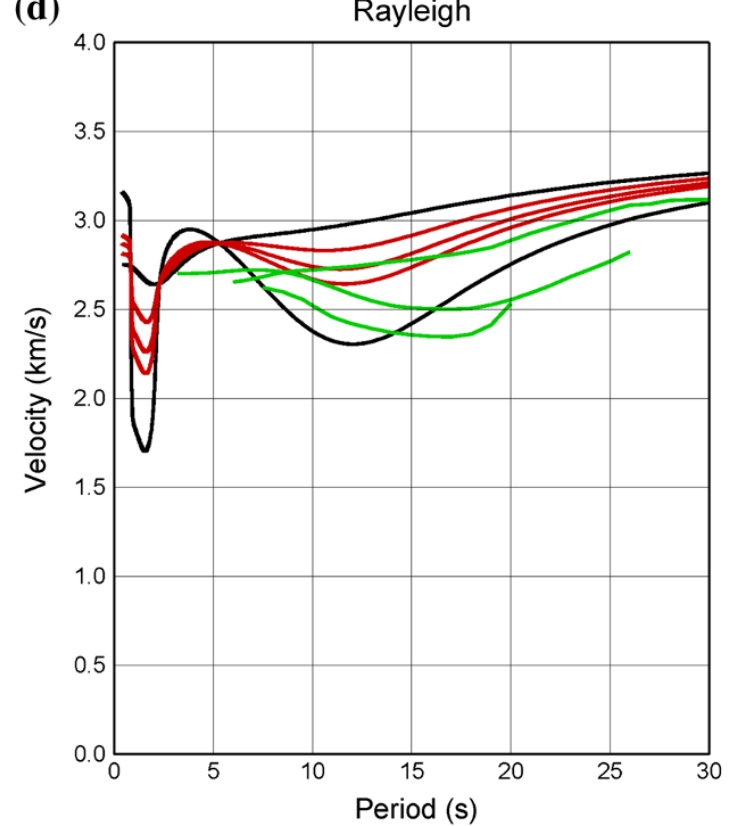

Fig. 6 Comparison between forward superimposed dispersion curves and the actual observed dispersion curves of Y43-Y103, Y32-Y105, and H17A-H18A. The shear wave velocity in the LVZ in $\mathbf{a}, \mathbf{b}, \mathbf{c}$, and $\mathbf{d}$ are 1.0, 1.2, 1.4, and 2.0. Forward dispersion curves by the crustal model are represented by two black lines, the red and green lines represent forward dispersion curves and the observed curves, respectively

Yellowstone region, but their study is more concerned with regional structure rather that the small-scale structures such as the magma chamber beneath the Yellowstone Caldera. Some tomographic models by previous studies had smooth velocity structure as they did not consider the a priori information of the LVZ (Gao et al. 2011; Hanson-Hedgecock et al. 2012; Wagner 2012). Our study considered the priori information and would provide more details about the LVZ than the normal tomography method. In addition, travel time of body wave and surface waves (i.e., dispersion) is only part of the data provided by seismic waveforms for resolving the Earth's internal structure. Recent studies demonstrate that waveform inversion can provide a more accurate and comprehensive study of the velocity 
(a)

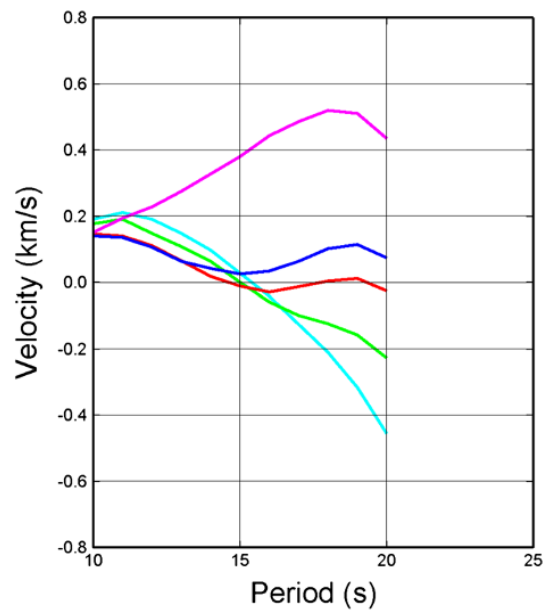

(b)

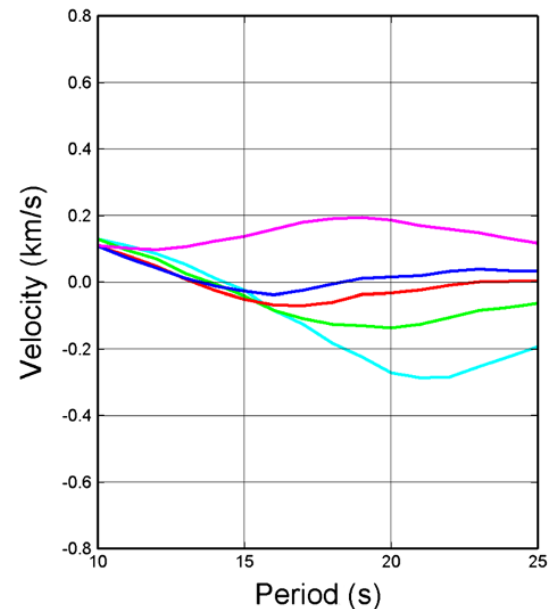

(c)

Misfit

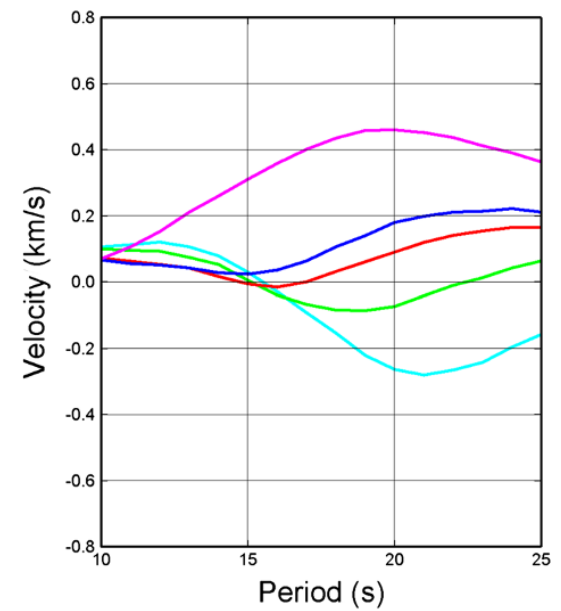

Fig. 7 The misfit curve between the forward dispersion curves and the observed dispersion curves of a Y43-Y103, b Y32-Y105, and $\mathbf{c}$ H17AH18A. The misfit curves which were calculated from the shear wave velocity of $1.0,1.2,1.3,1.4$, and $2.0 \mathrm{~km} / \mathrm{s}$ in the LVZ are represented by light blue, green, red, dark blue, and pink, respectively

(a)

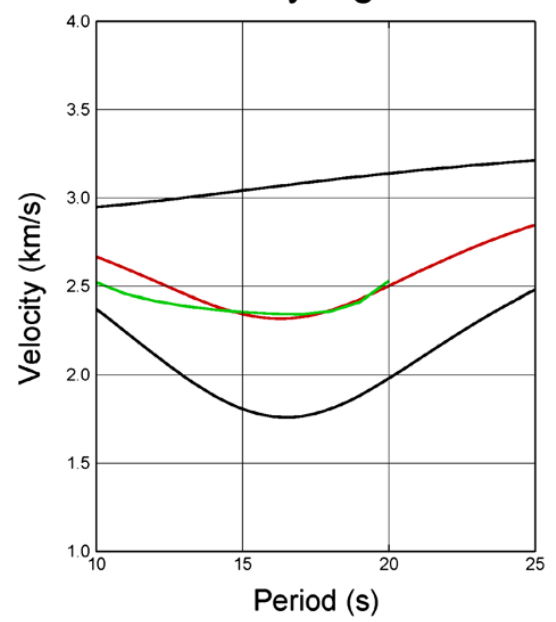

(b)

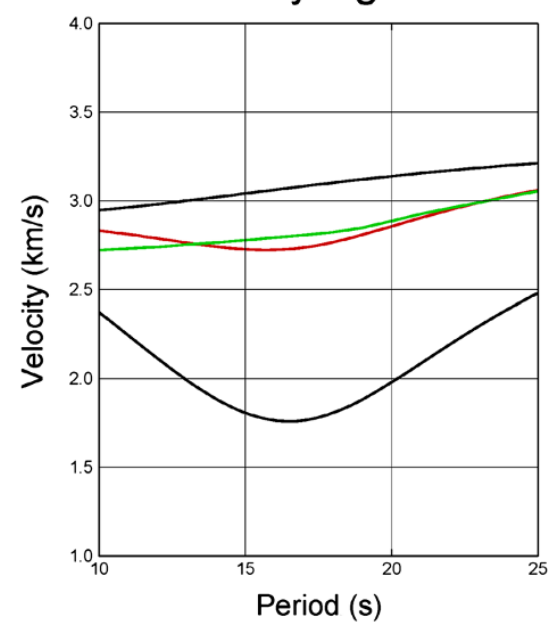

(c)

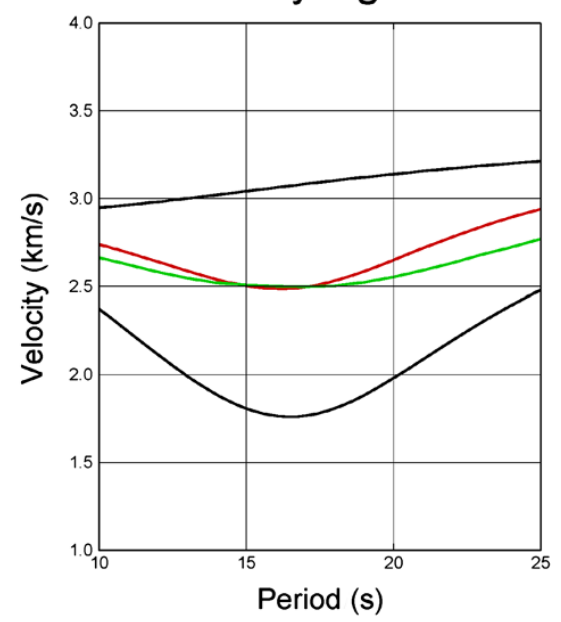

Fig. 8 Comparison between the observed dispersion curves and model synthesis results of a Y43-Y103, b Y32-Y105, and c H17A-H18A when the shear wave velocity was $1.3 \mathrm{~km} / \mathrm{s}$ in the LVZ. Forward dispersion curves by the crustal model are represented by two black lines, the red and green lines represent forward dispersion curves and observed curves, respectively

structure (Tape et al. 2009), which is an important topic for future work.

We used ambient seismic noise from regional stations to obtain short-period surface waves through cross-correlation, and we studied the shallow structure of the Yellowstone region through surface wave dispersion analysis. Assuming two 1D models are appropriate for the region outside and inside the magma chamber regions, respectively, we obtained a crustal model of the region outside of Yellowstone volcano and determined that the velocity of the magma chamber beneath the Yellowstone Caldera is $1.3 \mathrm{~km} / \mathrm{s}$, which falls in the range of
$1.2-1.4 \mathrm{~km} / \mathrm{s}$. With this velocity value, the surface wave dispersion calculated from our model is consistent with the previous observations. These results prove that largescale magma exists in the shallow crust of the Yellowstone volcanic region.

Acknowledgments We appreciate the valuable help from Dr. Huajian Yao. The seismic ambient noise waveform data were downloaded from IRIS. The surface wave processing software package (version 3.30) was provided by Professor Robert Herrmann at Saint Louis University. This project was supported by China Postdoctoral Science Foundation 2012M510043, 2013T60166, NSFC 41074032 and CAS KZCX2-EW-121. 


\section{References}

Aki K, Richards PG (1980) Quantitative seismology. WH Freeman and Company, San Francisco, pp 259-330

Bensen GD, Riotzwoller MH, Barmin MP et al (2007) Processing seismic ambient noise data to obtain reliable broad-band surface wave dispersion measurements. Geophys J Int 169:1239-1260

Bensen GD, Riotzwoller MH, Shapiro NM (2008) Broadband ambient noise surface wave tomography across the United States. J Geophys Res 113:B05306

Benz HM, Smith RB (1984) Simultaneous inversion for lateral velocity variations and hypocenters in the Yellowstone region using earthquake and refraction data. J Geophys Res 89:1208-1220

Campillo M, Paul A (2003) Long range correlations in the diffuse seismic coda. Science 299:547-549

Chang WL, Smith RB, Wicks C, Farrell JM, Puskas CM (2007) Accelerated uplift and magmatic intrusion of the Yellowstone Caldera, 2004 to 2006. Science 318:952-956

Christiansen RL (2001) The quaternary and Pliocene Yellowstone plateau volcanic field of Wyoming, Idaho, and Montana, US Geological Survey 729-G, p 145

Chu R, Helmberger D, Sun D, Jackson JM, Zhu L (2010) Mushy magma beneath Yellowstone. Geophys Res Lett 37:L01306. doi:10.1029/2009GL041656

Dal Moro G, Pipan M, Gabrielli P, Forte E, Sugan M (2007) Rayleigh wave dispersion curve inversion via genetic algorithms and marginal posterior probability density estimation. J Appl Geophys 61(1):39-55

Dorigo M (1995) Ant system: optimization by a colony of cooperating agents. IEEE Trans Syst Man Cybern 26(1):29-41

Dziewonski A, Anderson D (1981) Preliminary reference earth model. Phys Earth Planet Int 25:297-365

Dziewonski A, Mills J, Bloch S (1972) Residual dispersion measurement-a new method of surface wave analysis. Bull Seismol Soc Am 62:129-139

Fang L, Wu J (2009) Measurement of Rayleigh wave dispersion from ambient seismic noise and its application in north China. Acta Seismol Sin 31(5):544-554

Gao H, Humphreys ED, Yao H, van der Hilst RD (2011) Crust and lithosphere structure of the northwest U.S. with ambient noise tomography: Terrane accretion and Cascade arc development. Earth Planet Sci Lett 304:202-211

Girard G, Stix J (2012) Future volcanism at Yellowstone Caldera: insights from geochemistry of young volcanic units and monitoring of volcanic unrest. GSA Today 22(9):4-10

Hanson-Hedgecock S, Wagner LS, Fouch MJ, James DE (2012) Constraints on the causes of mid-Miocene volcanism in the Pacific Northwest US from ambient noise tomography. Geophys Res Lett 39:L05301. doi:10.1029/2012GL051108

Herrmann RB, Ammon CJ (2004) Surface waves, receiver functions and crustal structure. Computer Programs in Seismology, Version 3.30, Saint Louis University

Husen S, Smith RB, Waite GP (2004) Evidence for gas and magmatic sources beneath the Yellowstone volcanic field from seismic tomographic imaging. J Volcanol Geotherm Res 131:397-410

Julia J, Ammon CJ, Herrmann RB, Correig AM (2000) Joint inversion of receiver function and surface wave dispersion observations. Geophys J Int 143(1):99-112

Lin F, Moschetti MP, Ritzwoller MH (2008) Surface wave tomography of the western United States from ambient seismic noise: Rayleigh and Love wave phase velocity maps. Geophys J Int 173:281-298

Lin F, Tsai VC, Ritzwoller MH (2012) The local amplification of surface waves: a new observable to constrain elastic velocities, density, and anelastic attenuation. J Geophys Res 117:B06302. doi:10.1029/2012JB009208

Miller DS, Smith RB (1999) P and S velocity structure of the Yellowstone volcanic field from local earthquake and controlledsource tomography. J Geophys Res 104(15):105-115,121

Moschetti MP, Ritzwoller MH, Shapiro NM (2007) Surface wave tomography of the western United States from ambient seismic noise: Rayleigh wave group velocity maps. Geochem Geophys Geosyst 8:Q08010

Phillips JD, Duval JS, Ambroziak RA (1993) National geophysical data grids: Gamma-ray, gravity, magnetic and topographic data for the conterminous United States. US Geological Survey Digital Data Ser, DDS-9

Puskas CM, Smith RB, Meertens CM, Chang WL (2007) Crustal deformation of the Yellowstone-Snake River Plain volcanotectonic system: campaign and continuous GPS observations, 1987-2004. J Geophys Res 112:B03401. doi:10.1029/ 2006JB004325

Schutt DL, Dueker K, Yuan H (2008) Crust and upper mantle velocity structure of the Yellowstone hot spot and surroundings. J Geophys Res 113:B03310. doi:10.1029/2007JB005109

Shapiro NM, Campillo M (2004) Emergence of broadband Rayleigh wave from correlations of the ambient seismic noise. Geophys Res Lett 31:L07614

Shapiro NM, Campillo M, Stehly L et al (2005) High-resolution surface wave tomography from ambient seismic noise. Science 307:1615-1618

Shi Y, Jin W (1995) Genetic algorithms inversion of lithospheric structure from surface wave dispersion. Chin J Geophys 38(2):189-198

Stachnik JC, Dueker K, Schutt DL, Yuan H (2008) Imaging Yellowstone plume-lithosphere interactions from inversion of ballistic and diffusive Rayleigh wave dispersion and crustal thickness data. Geochem Geophys Geosyst 9:Q06004. doi:10. 1029/2008GC001992

Tape C, Liu Q, Maggi A, Tromp J (2009) Adjoint tomography of the southern California crust. Science 325:988-992

Wagner L, Fouch MJ, James DE, Hanson-Hedgecock S (2012) Crust and upper mantle structure beneath the Pacific Northwest from joint inversions of ambient noise and earthquake data. Geochem Geophys Geosyst 13, Q0AN03. doi:10.1029/2012GC004353

Waite GP, Smith RB (2002) Seismic evidence for fluid migration accompanying subsidence of the Yellowstone Caldera. J Geophys Res 107(B9):2177. doi:10.1029/2001JB000586

Weaver RL, Lobkis OL (2001) On the emergence of the Green's function in the correlations of a diffuse field. J Acoust Soc Am 110:3011-3017

Wicks CW, Thatcher W, Dzurisin D (1998) Migration of fluids beneath Yellowstone Caldera inferred from satellite radar interferometry. Science 282:458-462

Wicks CW, Thatcher W, Dzurisin D, Svarc J (2006) Uplift, thermal unrest and magma intrusion at Yellowstone Caldera. Nature 440:72-75

Xu G, Yao H, Zhu L, Shen Y (2007) Shear wave velocity structure of the crust and upper mantle in western China and its adjacent area. Chin J Geophys 50:193-208

Yang Y, Ritzwoller MH, Levshin AL (2007) Ambient noise Rayleigh wave tomography across Europe. Geophys J Int 168(1):259-274

Yang Y, Ritzwoller MH, Lin F-C, Moschetti MP, Shapiro NM (2008) Structure of the crust and uppermost mantle beneath the western United States revealed by ambient noise and earthquake tomography. J Geophys Res 113:B12310. doi:10.1029/ 2008JB005833

Yang Y, Zheng Y, Chen J et al (2010) Rayleigh wave phase velocity maps of Tibet and the surrounding regions from ambient seismic 
noise tomography. Geochem Geophys Geosyst Q08010. doi:10. 1029/2010GC003119

Yao H, vander Hilst RD, de Hoop MV (2006) Surface-wave array tomography in SE Tibet from ambient seismic noise and twostation analysis-I. Phase velocity maps. Geophys J Int 166:732-744

Yao H, Campman X, de Hoop MV, vander Hilst RD (2009) Estimation of surface wave Green's functions from correlation of direct waves, coda waves, and ambient noise in SE Tibet. Phys Earth Planet Int 177:1-11
Zheng Y, Yang Y, Ritzwoller MH, Zheng X, Xiong X, Li Z (2010) Crustal structure of the northeastern Tibetan plateau, the Ordos block and the Sichuan basin from ambient noise tomography. Earthq Sci 23:465-476

Zheng Y, Shen W, Zhou L, Yang Y, Xie Z, Ritzwoller MH (2011) Crust and uppermost mantle beneath the North China Craton, northeastern China, and the Sea of Japan from ambient noise tomography. J Geophys Res 116:B12312. doi:10.1029/ 2011JB008637 